1 Lauren D. Hayhurst ${ }^{1,2}$, Jonathan D. Martin ${ }^{3}$, Sarah J. Wallace ${ }^{4}$, Valerie S. Langlois ${ }^{4}$, Marguerite A. Xenopoulos ${ }^{3}$,

2 Chris D. Metcalfe ${ }^{3}$, Michael D. Rennie ${ }^{1,2}$

\title{
3 Multi-Level Responses of Yellow Perch (Perca flavescens) to a Whole-lake Nanosilver Addition Study
}

$4 \quad{ }^{1}$ Lakehead University, Department of Biology, Thunder Bay, ON, Canada

$5 \quad{ }^{2}$ IISD Experimental Lakes Area Inc., Winnipeg, MB, Canada

$6 \quad{ }^{3}$ Trent University, School of the Environment, Peterborough, ON, Canada

$7 \quad{ }^{4}$ Institut national de la recherche scientifique, Centre Eau Terre Environnement, Québec City, QC, Canada

8 LDH: lhayhurst@iisd-ela.org

9 JDM: jnthn.mrtn@gmail.com

10 SJW: sarah.wallace@ete.inrs.ca

11 VSL: valerie.langlois@inrs.ca

12 MAX: mxenopoulos@ trentu.ca

13 CDM: cmetcalfe@trentu.ca

14 MDR: mrennie@ lakeheadu.ca 


\section{ACKNOWLEDGEMENTS}

Funding for the whole-lake addition project was provided by the Natural Sciences and Engineering

17 Research Council (NSERC) of Canada through the Strategic Grants Program (No. 413230-2011) and matching

18 grants from Environment and Climate Change Canada (ECCC) to CDM and MDR. The IISD-ELA provided in-kind

19 support for the project. Lee Hrenchuk, Chandra Rodgers, Patrick Kennedy, Brandon Greenaway, and students

20 assisted with fish collection. Andrea Conine, Daniel Rearick, Joseph Tonin, and Daniel Gilchrist provided additional

21 field assistance. Michael Paterson, Holger Hintelmann, and Paul Frost contributed to the design of the whole-lake

22 experiment. Vince Palace and Paul Frost provided comments on earlier drafts of the manuscript. Support for

23 biomarker analyses was provided by the National Contaminants Advisory Group of Fisheries and Oceans Canada to

24 CDM and VSL. Mercury analyses, energy density analyses, and bioenergetics modelling were supported by

25 infrastructure funded by the Canadian Foundation for Innovation, NSERC Discovery, and support from IISD-ELA

26 and the Mitacs Accelerate Program. Emianka Sotiri analyzed 2012 samples for energy density. The Alberta Centre

27 for Toxicology for analyzed 2012 samples for mercury. Susan Mann (retired) and Hilary Pritchard from Northwest

28 Biodiversity and Monitoring Ageing Laboratory with the Ontario Ministry of Natural Resources and Forestry

29 provided training and age validation, Johane Joncas from the Lakehead University Environmental Laboratory

30 conducted methylmercury analyses, and Jane Kirk with Environment and Climate Change Canada assisted with

31 validation of mercury results. VSL and MDR hold Canada Research Chairs and are grateful for their generous

32 support. 


\section{ABSTRACT}

34 Silver nanoparticles (AgNP) are widely used as antibacterial agents in both commercial products and for industrial

35 applications. As such, AgNP has a high potential for release into freshwater environments. As part of a whole-lake

36 ecosystem experiment to evaluate the impacts of AgNP exposure at low $\mu \mathrm{g} / \mathrm{L}$ concentrations, we evaluated

37 biological responses in Yellow Perch (Perca flavescens) before, during, and after AgNP additions to a freshwater

38 lake. Yellow Perch were monitored for responses to in situ AgNP additions at the cellular (suite of biomarkers),

39 individual (growth, prey consumption, and metabolism), and population scale (abundance and gross prey

40 consumption). At the cellular level, several biomarkers of oxidative stress in liver tissues revealed down-regulation,

41 including decreased mRNA levels of catalase (cat) and glutathione peroxidase (gpx) in Yellow Perch collected

42 during AgNP exposure, and elevated ratios of reduced to oxidized glutathione (GSH:GSSG). At the individual level,

43 Yellow Perch bioenergetic models revealed that prey consumption and total metabolism significantly declined

44 during AgNP additions and remained depressed one year after AgNP addition. At the population level, Yellow

45 Perch densities declined, as did gross prey consumption by Yellow Perch after AgNP was added to the lake.

46 Together, these results reveal a holistic assessment of negative impacts of chronic exposure of environmentally

47 relevant AgNP concentrations ( $\mu \mathrm{g} / \mathrm{L}$ ) over multiple years on Yellow Perch at cellular, individual, and population

48 levels.

49 Keywords: $\quad$ IISD-Experimental Lakes Area; Mass-balance; Nanoparticles; Oxidative stress; Populations; 


\section{DECLARATIONS}

\section{Funding}

53 Funding for the whole-lake addition project was provided by the Natural Sciences and Engineering Research

54 Council (NSERC) of Canada through the Strategic Grants Program (No. 413230-2011) and matching grants from

55 Environment and Climate Change Canada (ECCC). The IISD-ELA provided in-kind support for the project. Support

56 for biomarker analyses was provided by the National Contaminants Advisory Group of Fisheries and Oceans

57 Canada. Mercury analyses, energy density analyses, biomarker analyses, and bioenergetics modelling were

58 supported by infrastructure funded by the Canadian Foundation for Innovation, NSERC Discovery, the Canada

59 Research Chairs program, and support from IISD-ELA and the Mitacs Accelerate Program (Awards No. 1465260:

60 Recovery of fish populations from environmental nanosilver release, August 2016).

\section{Conflicts of interest / Competing interests}

62 The authors declare no conflict of interest.

\section{Ethics approval}

64 Fish for the study were collected and handled under approval from the Animal Care Committee at Fisheries and

65 Oceans Canada (2012-13); the University of Manitoba (2014, AUP Nos. F14-007 and F14-008), Trent University

66 (2014-16; AUP Nos. 23694 and 23287), and Lakehead University (2015-16; AUP Nos. 1464693, 1464399,

67 1454655, and 1464656, and Biosafety Approval No. 1464768).

\section{Consent to participate}

69 All authors consent to participate in the publication.

\section{Consent for publication}

71 All authors provide consent for publication.

\section{Availability of data and material}

73 All data are available from the corresponding author on request.

\section{Code availability}

$75 \mathrm{R}$ code available from the corresponding author on request. 


\section{Authors' contributions}

77 CDM, MAX, and MDR were among the team of investigators that designed the whole-lake addition study. LDH, 78 JDM, and MDR collected fish. JDM conducted analysis of glutathione and TBARS biomarkers, SJW, and VSL

79 conducted biomarker analyses, and CDM compiled biomarker data. LDH modelled fish energetics and population

80 estimates. LDH, MDR, and SJW conducted statistical analysis and prepared figures. LDH, MDR, SJW, VSL, and

81 CDM wrote the manuscript. All authors contributed actively to the editing and final preparation of the manuscript. 


\section{INTRODUCTION}

Silver nanoparticles (AgNP) are a common antimicrobial agent in a wide range of consumer products, including medical products, clothing, and laundry detergents (Nowack et al. 2012; Buzea et al. 2007). As such, a major point of entry to the aquatic environment for $\mathrm{AgNP}$ is through point sources such as municipal wastewater and industrial discharges, and from diffuse sources such as run-off from agricultural fields treated with biosolids (Nowack et al. 2012; Maillard and Hartemann, 2013; Colman et al. 2014). In aquatic environments, AgNP may be a threat to aquatic life as it is acutely toxic to fish at high $\mu \mathrm{g} / \mathrm{L}$ or low $\mathrm{mg} / \mathrm{L}$ concentrations (Asharani et al. 2008; Chae et al. 2009; Farmen et al. 2012; Garner at al. 2015; Valerio-Garcia et al. 2017). There is evidence that the silver ions $\left(\mathrm{Ag}^{+}\right)$released from $\mathrm{AgNP}$ by dissolution may account for some of these toxic effects (Notter et al. 2014).

However, there also is evidence that the toxic effects of $\mathrm{AgNP}$ compared with $\mathrm{Ag}^{+}$occur through different pathways (Buzea et al. 2007; Pulit-Prociak et al. 2014). Although it is challenging to differentiate between toxicity from exposure to $\mathrm{AgNP}, \mathrm{Ag}^{+}$, and other transformation products (Kennedy et al. 2010; Laban et al. 2010; Wang et al. 2012), the evidence of differential routes for biological responses in aquatic organisms for AgNP compared to other transformation products may necessitate separate regulatory guidelines for AgNP. The Canadian Water Quality Guideline for total silver (Ag) is $0.25 \mu \mathrm{g} / \mathrm{L}$ for long-term exposure of freshwater organisms (CCME, 2015), but these guidelines may not be applicable to AgNP. Through recent advances in analytical methods, it is now possible to detect $\mathrm{Ag}^{+}$in water in particulate and dissolved forms at environmentally relevant concentrations (Furtado et al. 2016).

Modeling approaches have provided estimates of levels of AgNP in water at concentrations up to $1.3 \mu \mathrm{g} / \mathrm{L}$ (Gottschalk et al. 2013; Sun et al. 2014; Massarsky et al. 2014), but with continuous use and an increase in applications for AgNP in consumer products, concentrations in water may likely increase in the future (Massarsky et al. 2014). As reviewed by Murray et al. (2017a), almost all studies of biological impacts in fish exposed to AgNP have been conducted in controlled lab settings over relatively short periods of time and typically, at elevated concentrations. To date, there have been no studies conducted to evaluate sub-lethal effects from chronic exposure to low doses of AgNP in natural aquatic environments. In addition, responses at molecular and cellular levels in fish exposed to AgNP have not been linked to effects at higher levels of biological organization (i.e., individual and population levels) that may occur over months to years of exposure. 

uptake occurs via both respiration and digestion versus $\mathrm{Ag}^{+}$uptake through respiration alone (Buzea et al. 2007). As reviewed by Murray et al. (2017a), in studies with $\mathrm{AgNP}$ exposures ranging from 10-32,000 $\mu \mathrm{g} / \mathrm{L}$, fish have been

112 observed to bioaccumulate $\mathrm{Ag}^{+}$, with the highest concentrations observed in the gills and liver. Responses to $\mathrm{Ag}^{+}$ occurs primarily through the inhibition of the sodium-potassium pump in fish gill cells, which eventually leads to osmoregulatory failure as a result of a progressive net loss of sodium and chloride ions from the blood (Scown et al. 2010). In contrast, exposure to AgNP results in excess production of reactive oxygen species, which may cause damage to cellular DNA, or lipid peroxidation and protein modifications (Scown et al. 2010). Several laboratory

117 studies have shown that exposures of fish to AgNP can cause oxidative stress, as indicated by alterations to cellular antioxidant defense systems (Carlson et al. 2008; McShan et al. 2014; Valerio-Garcia et al. 2017; Bacchetta et al. 2017). A previous study conducted by our group showed that juvenile Yellow Perch (Perca flavescens) exposed to AgNP yielded alterations in the expression of antioxidant enzymes, as well as changes to the ratios of the reduced and oxidized forms of glutathione (Martin et al. 2017a). Biological responses also include increases in the levels of metallothionein (MT) in fish exposed to both $\mathrm{Ag}^{+}$and $\mathrm{AgNP}$ (Mayer et al. 2003; Chae et al. 2009; Martin et al. 2017a). Other studies with fish exposed to AgNP at concentrations ranging from $20-8,000 \mu \mathrm{g} / \mathrm{L}$ have shown that 124 exposure induces the release of cortisol, and metabolic impairment has been observed in fish exposed to $300 \mu \mathrm{g} / \mathrm{L}$ of AgNP (Murray et al. 2017a). However, most studies indicate that AgNP is generally less toxic than $\mathrm{Ag}^{+}$at equivalent concentrations (Scown et al. 2010; Wang et al. 2012; Murray et al. 2017a; Martin et al. 2017a). addition phases was monitored (Martin et al. 2018). Concentrations of Ag in the liver and gill tissue of both Yellow

130 Perch and Northern Pike rapidly increased during the AgNP addition phase and then declined during the post131 addition phase (Martin et al. 2018). In the present study, we evaluated the biological effects in Yellow Perch collected from this dosed lake in response to accumulation of Ag during the whole-lake experiment. The effects 133 were evaluated at multiple scales: at the cellular level through oxidative stress bioindicators, at the individual level 134 by examining growth and bioenergetics, and at the population level by monitoring population densities and gross prey consumption. At each level, we examined responses in Yellow Perch over the pre-addition, addition, and postaddition phases of the study. 
The whole-lake additions of AgNP that took place as part of this experiment have been described previously (Conine et al. 2018; Rearick et al. 2018; Martin et al. 2018). Briefly, AgNP was added to Lake 222, hereafter referred to as the AgNP lake, which is located at the International Institute for Sustainable Development -

142 Experimental Lakes Area (IISD-ELA) in northwestern Ontario, Canada. The AgNP lake is a small (i.e., 16 ha)

143 oligotrophic lake with a maximum depth of approximately $6 \mathrm{~m}$ and a stable thermocline that forms in the summer months at depths between 2 and $2.5 \mathrm{~m}$. AgNP was added in 2014 for 18 weeks, starting in mid-June and ending in

145 late October, and in 2015 for 14 weeks, starting in early May and ending in late August, for total AgNP additions in 1462014 and 2015 of approximately $9 \mathrm{~kg}$ and $6 \mathrm{~kg}$, respectively. The concentrations of $\mathrm{Ag}$ detected in both the 147 epilimnion and hypolimnion of AgNP lake during the addition phase were in the range of 1-10 $\mu \mathrm{g} / \mathrm{L}$, although the 148 levels were higher immediately adjacent to the site of addition into the lake (Conine et al. 2018; Rearick et al. 2018; 149 Martin et al. 2018).

The AgNP used to dose the AgNP lake was purchased in powder form from Nanostructured and Amorphous Materials, Inc. (NanoAmor, Los Alamos, NM., USA). The AgNP was capped with

152 polyvinylpyrrolidone (PVP) and had a manufacturer specified average particle size of 30-50 nm. Particles were 153 suspended to a nominal concentration of $1 \mathrm{mg} / \mathrm{mL}$ in deionized water containing a $0.025 \%(\mathrm{w} / \mathrm{v})$ solution of gum arabic (Sigma Aldrich, Oakville, ON, Canada) which was added as an organic stabilizer. The particles were

155 suspended by milling with a commercial rotor-stator dispersion mill (Kady® International, Scarborough, ME., USA) 156 as described in detail by Martin et al. (2017b). The hydrodynamic diameter of nanoparticles in these stock suspensions were determined by dynamic light scattering to be $39.3 \pm 3.63 \mathrm{~nm}$ (Martin et al. 2017b), consistent with

158 the manufacturer's specifications.

\section{Fish collections}

Perch for biomarker analyses were collected under a protocol approved through the Animal Care

161 Committee at Trent University (AUP Nos. 23694 and 23287). Perch collected for population abundance estimates 162 and bioenergetics analysis were collected during 2012-13 under a protocol approved through Fisheries and Oceans 163 Canada and the Animal Care Committees at the University of Manitoba (AUP No. F14-007), and during 2014-17 164 through Lakehead University (AUP No. 1464693). 

and from three reference lakes (i.e., Lake 239, Lake 240, Lake 383). Subsequently, Yellow Perch were collected

167 from the AgNP lake and from Lake 239, hereafter referred to as the reference lake, during AgNP additions in 2014 168 and 2015 (i.e., Years 1 and 2 of addition, respectively), and during the post-addition phase in 2016, as shown in Table 1. Perch collected for biomarker studies were sacrificed on-site by an overdose of tricaine methanesulfonate

170 (TMS) anaesthetic purchased from Argent Chemical Laboratories (Redmond, WA., USA) dissolved in lake water.

171 Euthanized fish were then weighed and measured for fork length. Liver tissues were removed and placed on dry ice

172 for transport to the lab where they were stored in liquid nitrogen or in a $-80^{\circ} \mathrm{C}$ freezer until thawed for biomarker

173 analysis. Liver tissues were analyzed for both molecular and cellular biomarkers from Yellow Perch collected in

174 Year 1 addition, but only cellular biomarkers were analyzed in the livers of Yellow Perch collected in Year 2 175 addition (Table 1).

Over the months of May to October in 2012-2016, Yellow Perch were captured in trap and seine nets from

177 the AgNP lake and reference lake for population estimates and for bioenergetics analysis (Table 2). During 2012,

178 2014, 2015, and 2016, up to $n=5$ Yellow Perch from the AgNP lake and reference lake were sacrificed in the 179 summer and fall for bioenergetic analyses in each of the following size classes: $\leq 50 \mathrm{~mm}, 51-70 \mathrm{~mm}, 71-90 \mathrm{~mm}, 91-$ $180110 \mathrm{~mm}, 111-130 \mathrm{~mm}, 131-150 \mathrm{~mm}, 151-170 \mathrm{~mm}$, and >170 mm, which roughly corresponded to age cohorts 181 (Hayhurst 2018). Fish were euthanized with an overdose of TMS, placed in labelled Whirl-Pak® bags and frozen at $-20^{\circ} \mathrm{C}$. Fish were later thawed in the laboratory for dissection and removal of ageing structures, stomach contents,

183 and muscle tissue. Ages of Yellow Perch were determined by examination of opercula and fin rays, a subset of 184 which were verified by third-party blind assessment (Susan Mann, pers. comm.). Stomachs were removed and preserved in $95 \%$ ethanol for gut content analysis. Finally, muscle tissue was taken above the lateral line and below 186 the dorsal fin, placed in a plastic micro-centrifuge vial and frozen at $-20^{\circ} \mathrm{C}$ for $\mathrm{Hg}$ analysis (see "Bioenergetics 187 modelling" below). To obtain size distribution and population estimates of Yellow Perch in the AgNP lake and reference lake, 189 all captured fish were anaesthetized using a mild solution of TMS, measured for length on-site, given a season- and 190 year-specific fin nick to indicate capture history, examined for pre-existing fin nicks indicating previous capture, and released upon recovery into the lake. Population estimates of Yellow Perch in both the AgNP lake and reference lake were estimated using open population mark-recapture methods using the POPAN method in Program Mark 
(Supplementary Information S5). All assumptions of the open population POPAN estimation method were met (Suppl. Info. S3).

\section{Biomarkers}

During the pre-addition phase and the first year of additions, the expression of four genes related to oxidative stress were measured in liver tissue: glutathione peroxidase 3 ( $g p x)$, glutathione reductase ( $g s r)$, catalase (cat), and superoxide dismutase $1(\operatorname{sod} 1)$. In addition, measurements were made of the gene expression of metallothionein $(m t)$, heat shock protein 70kDa ( $h s p 70)$, heat shock protein 90kDa (hsp90), and cytochrome P450 (cypla). Gene expression was assessed through quantitative PCR (qPCR) following MIQE guidelines (Bustin et al. 2009) using primers previously designed and validated (Pierron et al. 2009; Martin et al. 2017a; Table S1.1). The analysis was run with GoTaq® qPCR Master Mix (Promega, Madison, WI, USA) containing BRYT Green® dye with each sample in duplicate. Each qPCR assay included a negative template control as well as a negative reverse transcriptase control to ensure contamination was not present. Relative mRNA levels of the genes of interest were normalized to the expression of the reference gene beta-actin $(a c t \beta)$, which did not differ with treatments. Gene expression changes were reported as fold-changes relative to the control. For more details, refer to supplementary information. and oxidized glutathione (GSSG) in Yellow Perch livers were measured spectrophotometrically in units of mmol per gram wet weight using a glutathione reductase catalyzed cycling assay with 5,5'-dithio-bis(2-nitrobenzoic acid (DTNB), as described previously by Martin et al. (2017a). The reduced form of glutathione (i.e., GSH) was

212 calculated as the difference between measured $\mathrm{GSH}_{\text {tot }}$ and GSSG. Lipid peroxidation was measured spectrophotometrically using the thiobarbituric acid reactive substances (TBARS) assay, as described by Martin et 214 al. (2017a).

\section{Bioenergetics modelling}

Following the approach described by Ferriss and Essington (2014), Yellow Perch energetics in the AgNP

217 lake and reference lakes were modelled for each year from the beginning of the growing season (i.e., summer) to the end of the growing season (i.e., fall). We used the MeHg accumulation model (MMAM) described by Trudel et al. 

estimate for absolute $C$ ( $\mathrm{g}_{\text {food }} /$ day) that was then used in the Wisconsin Bioenergetics Model (WBM) described by

222 Hanson et al. (1997) to estimate the total metabolism, $R_{T}$ (J/day) for Yellow Perch in both the AgNP lake and 223 reference lake during the pre-addition, addition, and post-addition phases of the study (see Equation 3 below). The MMAM approach has been validated and field tested against other methods of estimating consumption and performs well (Trudel et al. 2000), and the approach has been successfully implemented previously to demonstrate changes or differences in fish consumption related to ecomorphological differences (Trudel et al. 2001), prey community differences (Pazzia et al. 2002), predator densities (Rennie et al. 2010) and species invasions (Rennie et al. 2012). MeHg in Yellow Perch was assumed to be $100 \%$ of the measured Hg concentrations (Rennie et al. 2005). The analytical methods for determining the concentrations of $\mathrm{Hg}$ and $\mathrm{MeHg}$ in fish tissues are described in Supplementary Information S4. For modelling purposes, it was assumed that there was negligible MeHg uptake from water and that all uptake was from dietary sources (Trudel et al. 2000). Juvenile Yellow Perch are zoobenthivorous and transition to piscivory as they grow. Analysis of gut contents from the lakes that we monitored indicated that Yellow Perch $\geq 3$ years of age from the reference lake were piscivorous, but piscivory was not observed in Yellow Perch from the AgNP lake (Hayhurst, 2018). Perch catches during this study were highly female-biased, which is common among Yellow Perch populations (Rennie and Venturelli, 2015). Therefore, we combined input parameters by age cohort that were overwhelmingly represented by female fish and interpreted the results as representative of populations with a substantial female-bias.

According to the MMAM described by Trudel et al. (2000), the increase in the estimated concentrations of $\mathrm{MeHg}$ in Yellow Perch over the growing season can be represented by:

Equation (1)

$$
d H g / d t=\left(\alpha \cdot C_{d} \cdot C\right)-(E+G+K) \cdot H g
$$

241 Where: $\mathrm{Hg}$ is the estimated amount of $\mathrm{MeHg}$ in the fish at time 0 and $t, \alpha$ is the assimilation efficiency of $\mathrm{MeHg}$ 242 from food, $C_{d}$ is the $\mathrm{MeHg}$ content of the food (estimated from diet and $\mathrm{MeHg}$ in collected prey from each lake; 243 Table $\mathrm{S} 2.2), C$ is the absolute ingestion rate ( $\left.\mathrm{g}_{\text {food }} / \mathrm{day}\right)$ integrated over the time period, $E$ is the elimination rate of $244 \mathrm{MeHg}$, and $G$ is the mass-specific growth rate ( $\mathrm{g}_{\text {fish }} /$ day). Instantaneous loss to gonads $(K)$ was set to zero as we did 245 not model Yellow Perch growth over the spawning season. All other model parameters are taken from Rennie et al. 246 (2008). 

solve for absolute consumption, $C$ ( $\left.\mathrm{g}_{\mathrm{food}} / \mathrm{day}\right)$ :

$$
C=\left[H g_{t}-H g_{0} \cdot e^{-(E+G+K) t}\right] /\left[\alpha \cdot C_{d} \cdot\left(1-e^{-(E+G+K) t}\right)\right] \cdot(E+G)
$$

The output from the MMAM provided the estimate for $C$ that was used in the WBM. This model, which was described by Hanson et al. (1997) is expressed as:

$$
W_{t}=W_{0}+\left[C \cdot E D_{\text {Prey }}-\left(F+U+R_{T}\right)\right] / E D_{F i s h}
$$

Where: $W_{t}$ is final fish weight, $W_{0}$ is initial weight, $E D_{\text {Prey }}$ is energy density of prey, $F$ is losses due to egestion, $U$ is losses due to excretion, $R_{T}$ is losses due to metabolism (J/day), and $E D_{F i s h}$ is energy density of fish (measured lake-specific $E D_{F i s h}$ values). Examination of gut contents revealed no significant difference in prey rations during and after AgNP additions, or between seasons. $E D_{\text {Prey }}$ values were estimated for each lake and maturity, since piscivory was only observed in the reference lake. Prey energy density values were calculated based on Yellow Perch gut contents and published values (Table S4.3). Yellow Perch energy densities were estimated directly from samples taken in 2012. Energy densities in both lakes were found to be independent of body size (Hayhurst, 2018), so mean values were used (i.e., AgNP lake: $4876 \pm 461$; reference lake: $4501 \pm 588$ ). Many of the functions in both the MMAM $(E)$ and $\operatorname{WBM}\left(C, R_{T}\right)$ are temperature dependent and daily mean lake temperatures were collected to parameterize these functions in the models (Supplementary Information S2). To evaluate changes in size-at-age and body condition, we examined fish collected during summer and fall only to avoid the influence of spring spawning on body shape and mass. Changes in size-at-age were evaluated over time using fork length at age. Body condition was estimated as relative weight for all Yellow Perch over $100 \mathrm{~mm}$ total length, using equations described by Willis et al. (1991).

\section{Population estimates}

Population estimates were calculated using the POPAN sub-module in Program Mark (White and Burnham, 1999), based on batch-marking of Yellow Perch fins with seasonal nicks that were observed between capture periods. The POPAN sub-module is a modification of the Cormack-Jolly-Seber (CJS) model. Where the CJS

271 model considers the marked cohort of animals only and follows the subsequent recaptures, the modified POPAN

272 formulation uses ratios of unmarked versus marked individuals to permit estimates of population size, survival, and

273 capture probabilities (Arnason et al. 1998). Model fitting procedures and details are outlined in Supplementary

274 Information S5. While sampling sites in the relatively small AgNP lake (i.e., 16 ha) provided a good representation 
275 of the shoreline habitat occupied by Yellow Perch, sampling in the much larger reference lake (i.e., 54 ha) was

276 limited to two bays with a combined area of 0.76 ha. Therefore, population estimates are reported as numbers per

277 unit area, based on the relative areas sampled in each lake (i.e., 16 ha in the AgNP lake, 0.76 ha in the reference

278 lake).

279

\section{Gross consumption}

Using population estimates for Yellow Perch and cohort-estimated consumption $(C)$, gross consumption of prey by Yellow Perch was estimated for each lake. As only a limited number of Yellow Perch were sacrificed and aged in each season, predicted ages were assigned to all captured individuals using size-at-age relationships to determine the proportion of the population within each age class. Lake-specific size-at-age relationships were predicted and analysed in R using age-length keys for unequal interval age cohorts (Ogle, 2016; Isermann and Knight, 2005). Proportions of Yellow Perch with known ages were assessed per age cohort, as outlined in Kimura (1977) to provide an age sample against which the age-length key was run. This provided an assigned age to all captured Yellow Perch in each population and allowed for a proportional estimate of the population in each cohort which could be applied to estimated population estimates for each capture period.

Absolute consumption estimates ( $g_{\text {food }} /$ day) for each cohort aged 1-6 were converted to mass-specific rates ( $\mathrm{g}$ of prey per $\mathrm{g}$ of fish per day; Figure S4.1) and multiplied by the estimated number of fish in each cohort (yielding total daily g of prey consumed in the population for each cohort) and then summed across cohorts within each period (Rand and Steward 1998). Population estimates for each year were averaged across sampling periods, then subdivided among age classes based on the annual proportion of Yellow Perch caught in each lake (Supplementary Information S4). This value estimated for each lake was then multiplied by the number of days from May $1^{\text {st }}$ to October $31^{\text {st }}$, which is the estimated period of the year over which Yellow Perch feed to yield estimates of gross prey consumption. Prey consumption by Yellow Perch over the winter months (between November $1^{\text {st }}$ and April $30^{\text {th }}$ ) was assumed to be negligible (Eckmann, 2004). Missing consumption estimates for a particular cohort were replaced with nearest (i.e., spring-summer) bioenergetics values. Excluded from gross consumption estimates were young-of-the-year (YOY; age 0) Yellow Perch, which were too small to effectively tag within a season, and Yellow Perch age 7 or older, which comprised $<0.9 \%$ of the annual populations in the AgNP lake, and $<1.5 \%$ of the annual populations in the reference lake (Table S4.1). 
By excluding YOY fish, which were estimated to comprise between $29 \%$ and $52 \%$ of the population in the

AgNP lake, and between $16 \%$ and $54 \%$ of the population in the reference lake based on age-key assignments to all captured fish (Hayhurst, 2018), and excluding age $\geq 7$ Yellow Perch (too few fish to accurately apply bioenergetic models to), gross consumption estimates for Yellow Perch in the AgNP lake represented 48\% of the total sampled population during the pre-addition phase (2012), 51\% of the total sampled population during the first year of AgNP additions in 2014, 70\% during the second year of AgNP additions in 2015, and 60\% of the total sampled population during the post-addition phase in 2016 (Table S4.1). For Yellow Perch from the reference lake captured over the same time periods, gross consumption estimates represented $46 \%$ in $2012,83 \%$ in $2014,62 \%$ in 2015 , and $64 \%$ of the population in 2016 .

\section{Statistical analysis}

Outliers in the gene expression data were removed using the robust regression and outlier removal method at $1 \%$. For statistical analysis of biomarker data, the Shapiro-Wilk Goodness of Fit test was performed to verify normality and Levene's test was performed to test for equal variances among treatments, which indicated that logtransformations were required to meet these assumptions. Treatments in the analysis represented the time of Yellow Perch collection (Phase: pre-addition years, Year 1 AgNP addition in August, Year 1 AgNP addition in October), and conditions in the lakes (Lake: AgNP lake, reference lake). Differences in biomarker responses among Yellow Perch collected at different times and locations were tested using two-factor ANOVA, followed by post-hoc comparisons using a Tukey's Honestly Significant Difference (HSD) test. All statistical analyses were performed using Prism (version 6, GraphPad Software, California, USA).

Similarly, data for levels of $\mathrm{GSH}_{\text {tot }}$, GSSG, GSH, the ratio of GSH:GSSG, and TBARS were analyzed using a two-factor ANOVA, followed by a Tukey's HSD test in R (version 3.6.2, R Core Team 2019). Type III sums of squares were used to account for unequal sample sizes among groups. Treatments in the analysis represented the year and season of Yellow Perch collection (Phase: pre-addition Year 1, pre-addition Year 2, Year 1 AgNP addition for August and October, and Year 2 AgNP addition in May and October). Log-transformations to response variables generated normally distributed and homogeneous residuals in all cases for GSH. For TBARS, an Anderson-Darling test indicated that residuals were not distributed normally $(p=0.04)$, and neither log nor square root transformation improved residual distributions. As such, we present results for untransformed TBARS data. 

derived from the bioenergetics models were analyzed in R 3.6.2 (R Core Team, 2019), first using a test of

331 heterogeneity of slopes (to verify homogeneity of slopes among experimental periods) and then ANCOVA with logtransformed mass as a covariate (Quinn and Keough, 2002). In each case, Anderson-Darling tests for normality and Levene's test for homogeneity of variance were performed and demonstrated that assumptions of the tests were met.

334 Differences among intercepts were estimated using tests of planned comparisons among adjusted means between the pre-addition, AgNP addition, and post-addition periods (Quinn and Keough, 2002). Changes in fork length-at-age were evaluated over time using tests for heterogeneity of slopes, as mean size increased linearly with age in our populations. Changes in body condition were evaluated using a two-factor ANOVA, with year of sampling and lake (as well as their interaction) as treatments. Body condition residuals were normally distributed and homogeneous among groups. Changes in Yellow Perch abundance over time and gross consumption were assessed visually with plots of mean densities over time.

\section{RESULTS}

\section{Cellular responses}

For most of the genes studied, there were significant interaction between the time of collection (phase) and the lake they were sampled from, indicating different temporal responses in gene expression between the experimental and reference lakes (Figure 1; Figure S1.1; Table S1.2). There was a significant reduction in the expression of gpx in Yellow Perch collected from the AgNP lake in October of the first year of AgNP additions, relative to Yellow Perch from the same lake during the pre-addition phase, and relative to Yellow Perch from the reference lake collected in October (Figure 1). In addition, the expression of $m t$ was down-regulated in Yellow Perch collected from the AgNP lake in October of the first year of AgNP additions relative to Yellow Perch from the same lake during the pre-addition phase and relative to Yellow Perch from the reference lake collected in October (Figure 1). Significant interactions in gene expression among fish from different collection phases and between lakes were

352 also observed for cat, cypla, hsp70, and $h s p 90$ (Table S1.2), demonstrating patterns of down-regulation following AgNP exposure in almost all genes associated with oxidative stress (i.e., all except $g s r$ ). We observed a significant up-regulation of $g s r$ in Yellow Perch from the AgNP lake collected in October during the first year of AgNP

355 addition compared to Yellow Perch from the same lake before AgNP additions (Figure 1), though a similar pattern was also observed in the reference lake. 

whereas there were no significant differences among mean levels of GSSG (2-factor ANOVA, $p>0.1$ for both main effects and interaction; Figure 2B). Concentrations of GSH increased significantly by October of the first year of AgNP additions, and remained elevated through the second year of exposure, whereas there was no similar change in GSH in the reference lake (Figure 2A). Patterns in levels of $\mathrm{GSH}_{\text {tot }}$ were identical to those observed in GSH (data not shown). The ratio of reduced to oxidized glutathione demonstrated a pattern similar to GSH, being elevated in Yellow Perch livers at four months after AgNP additions, and remaining elevated for the second year of additions, with no significant change in Yellow Perch from the reference lake (2-factor ANOVA, Phase $\times$ Treatment interaction: $F_{5,52}=15.2, p<0.0001$; Figure 2C). There were no significant differences observed in the levels of liver tissue TBARS among Yellow Perch collected from the AgNP lake and reference lake over the study (2-factor ANOVA, $p>0.2$ for all main effects and interaction; Table S1.3).

\section{Individual responses}

Accumulation of silver in Yellow Perch liver and gill tissues began immediately after the first addition of AgNP to the experimental lake, continued to increase in the second year of additions and declined rapidly during the

372 post-addition phase. The results of these findings are described in detail in Martin et al. (2018). Briefly, the mean 373 concentrations of Ag in the livers of Yellow Perch from the AgNP lake increased from pre-addition levels of $20 \pm$

$3740.4 \mathrm{ng} / \mathrm{g}$ wet weight to $472 \pm 134 \mathrm{ng} / \mathrm{g}$ wet weight in October after the second year of AgNP additions. The

375 concentrations of $\mathrm{Ag}$ in Yellow Perch from the reference lake remained at concentrations similar to the pre-addition

376 levels in Yellow Perch from the AgNP-added lake (Martin et al. 2018).

Bioenergetic consumption estimates declined after AgNP additions. Slopes of Yellow Perch consumption

378 with body mass were equivalent among time periods (pre-addition, AgNP addition, and post-addition) in the AgNP 379 lake (Test for heterogeneity of slopes, $F_{2,13}=0.8, p=0.47$ ). However, intercepts for consumption were significantly different in the AgNP lake over the different phases of the study (ANCOVA, $F_{2,15}=4.8, p=0.024$; Figure $3 \mathrm{~A}$ );

381 consumption rates for Yellow Perch were greatest prior to AgNP additions and were significantly reduced during 382 AgNP additions $(t=-2.7, p=0.009)$ and following AgNP additions $(t=-2.8, p=0.012$; Figure 4.1A). There were no significant differences between consumption rates in Yellow Perch during additions relative to the Yellow Perch sampled after AgNP additions $(t=0.41, p=0.7)$. 
Yellow Perch from the reference lake showed two distinct trajectories for both consumption and total metabolism, with one trajectory for zoobenthivorous life stage (ages 1-2), and the other for piscivorous life stages (ages 3 to 6; Figure 3B; Hayhurst 2018). As such, formal comparisons among zoobenthivorous Yellow Perch from the reference lake were only possible by comparing 2014-2015 and 2016, as only a single consumption estimate was available for 2012 zooplanktivorous fish (Figure 3B). Slopes among time periods (2014-15 vs. 2016) were statistically indistinguishable for zooplanktivorous Yellow Perch from the reference lake $\left(F_{1,1}=0.0004, p=0.99\right)$. Intercepts among time periods from the ANCOVA model were also not significantly different for consumption estimates of zooplanktivorous Yellow Perch from the reference lake $\left(F_{1,2}=8.3, p=0.10\right)$. For piscivorous Yellow Perch from the reference lake, neither slopes $\left(F_{2,7}=0.07, p=0.9\right)$ nor intercepts $\left(F_{2,9}=2.8, p=0.11\right)$ were different among time periods (Figure 3B).

Like consumption, bioenergetic estimates of total metabolic costs also declined in Yellow Perch after AgNP additions. Slopes for total metabolic rates with body size were equivalent among time periods (pre-addition, AgNP addition, and post-addition) for Yellow Perch from the AgNP lake (Test for heterogeneity of slopes, $F_{2,13}=$ $1.2, p=0.34)$. Intercepts in the ANCOVA model for total metabolic costs with body size were significantly different among experimental phases for Yellow Perch from the AgNP lake when Yellow Perch energy densities were increased by the standard error of the mean estimate $\left(F_{2,15}=3.85, p=0.045\right.$; Figure $\left.3 \mathrm{C}\right)$. When the mean energy density value was used, differences were very close to the significance value of $\alpha=0.05\left(F_{2,15}=3.65, p=0.051\right)$. Metabolic costs were greatest in Yellow Perch prior to AgNP additions and declined significantly during AgNP additions $(t=-2.4, p=0.016)$ and after AgNP additions $(t=-2.5, p=0.019)$ relative to initial conditions. There was no significant difference between metabolic costs for Yellow Perch captured during AgNP additions versus after AgNP additions $(t=0.37, p=0.6)$. Similar to consumption estimates, formal comparisons among zoobenthivorous

406 Yellow Perch from the reference lake were only possible by comparing data from 2014-2015 and 2016 (Figure 3D).

407 Slopes were similar among time periods for zooplanktivorous fish from the reference lake $\left(F_{1,1}=0.0003, p=0.99\right)$.

408 However, metabolic costs for zoobenthivorous Yellow Perch in the reference lake were significantly different 409 between time periods $\left(F_{1,2}=25, p=0.04\right)$. Total metabolic costs were lower in 2014-2015 compared to $2016(t=-$ 410 5.0, $p=0.008$; Figure 3D). For piscivorous Yellow Perch from the reference lake, while we similarly observed no 411 difference in slopes among time periods $\left(F_{2,7}=0.43, p=0.7\right)$, we did observe differences among time period 412 intercepts $\left(F_{2,9}=9.34, p=0.006\right)$. Metabolism rates of piscivorous Yellow Perch were significantly lower in the 
reference lake during 2014-15, compared to fish collected in $2012(t=-3.1, p=0.008)$ and $2016(t=-3.79, p=$ 0.002). There was no significant difference between the respirometric rates of Yellow Perch collected from the 415 reference lake in 2012 and $2016(t=0.13, p=0.55)$. $<0.0001)$. In Yellow Perch from the AgNP lake, sizes of older age classes appeared to be lower in the years when AgNP was added (i.e., 2014, 2015) and the year following the additions (2016) compared with 2012; that is, before any AgNP was added to the lake. Slopes of FL with age were also different in the reference lake among years (Figure 4B; $F_{3,274}=9.1, p<0.0001$ ). In Yellow Perch from the reference lake, size-at-age data for 2014 and 2015 appeared to group more closely with data from 2012. In the reference lake, 2016 appears to have been a poor year for Yellow Perch growth, with the size of Yellow Perch changing very little from the preceding age class (Figure 5B). For body condition data, there was a significant interaction among lake and year of fish collection $\left(F_{3,225}=\right.$ 2.79, $p=0.04$; Figure 5A). Body condition in Yellow Perch from the AgNP lake did not differ over time but was lower during 2014-2016 relative to 2012 in Yellow Perch from the reference lake (Tukey HSD, 2012 vs. 2014, $p=$ $0.004)$.

\section{Population responses}

Densities of Yellow Perch were higher in the AgNP lake than in the reference lake. However, temporal trends differed significantly between populations. For Yellow Perch from the AgNP lake, the population density was nearly halved over the course of the study, from 13000/ha during the pre-addition phase to just over 7000/ha postaddition, with no sign of recovery in population density following the cessation of AgNP additions (Figure 5B). By contrast, the Yellow Perch population in the reference lake was relatively stable at around 3000/ha over the entire study period. additions was less than $50 \%$ of pre-addition estimates (Figure 6A). Consumption rates remained suppressed, at approximately half of pre-addition levels during the second year of AgNP additions (2015) and post-addition (2016).

437 By contrast, gross prey consumption in the reference lake actually increased during the study period (Figure 6A), 438 though consumption rates in Yellow Perch from this lake were lower on average compared to Yellow Perch from the AgNP lake over the entire course of the study. Dividing the gross consumption data into estimates for smaller

440 (age 1-2) and larger (age 3-6) age classes revealed that gross consumption by juvenile Yellow Perch (i.e., age 1-2) in 

following the cessation of AgNP additions in 2016 (Figure 6B). By contrast, gross consumption in age 3-6 Yellow

443 Perch from the AgNP lake declined by approximately 1/3 during AgNP additions and fell to less than $1 / 5$ of pre444 addition levels during the post-addition phase in 2016 (Figure 6C).

\section{DISCUSSION}

Yellow Perch exposed to AgNP clearly exhibited negative biological responses during the additions of AgNP that were not observed during the same period in Yellow Perch collected from a reference lake. This study is unique as we were able to evaluate responses at all three levels of biological organization (cellular, individual, and population levels), indicating linkages between responses at the cellular level to changes in individual fish to impacts at the population level for Yellow Perch, due to AgNP exposure at environmentally relevant concentrations.

At the cellular level, we observed a down-regulation of glutathione peroxidase 3 ( $g p x$ ), which catalyzes the oxidation of peroxides using electrons from GSH in the livers of Yellow Perch collected during the first year of AgNP addition. The levels of mRNA for expression of glutathione reductase ( $g s r$ ), which catalyzes the turnover of GSH, also increased significantly in Yellow Perch after AgNP addition. Although the mRNA levels of these genes only indicate an increase in transcription, these changes are consistent with the overall increase of $\mathrm{GSH}_{\mathrm{tot}}, \mathrm{GSH}$, and the mean ratios of reduced to oxidized glutathione (GSH:GSSG) observed in the liver. The increases in GSH and GSH:GSSG ratios were seen both in the liver tissues of Yellow Perch collected in October during the Year 1 of AgNP additions and in May to August of Year 2 of AgNP additions. These results are also consistent with the elevated GSH:GSSG ratios in the liver tissues of juvenile Yellow Perch exposed in the laboratory to AgNP purchased from the same commercial source and prepared in the same way as the AgNP added to the lake (Martin et al. 2017a). Glutathione is an important antioxidant synthesized in the cell by glutathione cysteine ligase and glutathione synthetase and contributes to the ability of the cell to scavenge ROS, thereby protecting against oxidative stress (Hayes and McLellan, 1999).

Overall, the increase in $\mathrm{GSH}_{\mathrm{tot}}, \mathrm{GSH}$, and the GSH:GSSG ratios and associated changes in the gene expression of enzymes involved in the redox process indicated that hepatocytes in the liver of Yellow Perch exposed to AgNP may be responding to the increased oxidative stress from AgNP and transformation products. However, an increase in lipid peroxidation (i.e., an indicator of cellular damage) as measured by the TBARS assay was not observed in the livers of Yellow Perch collected from the AgNP lake over the period of AgNP additions. A similar 
response was observed in golden gray mullet (Liza aurata) collected from a mercury contaminated site in Portugal, where there was evidence of extensive oxidative stress in the gills of these fish, but no evidence of lipid peroxidative damage (Cappello et al. 2016). The authors of this study concluded that there were alternative mechanisms for preventing lipid peroxidation associated with enhancement of the membrane stabilization/repair processes. Surprisingly, there was a down-regulation of the metallothionein gene $(m t)$ in Yellow Perch collected during AgNP addition. In a previous laboratory study, juvenile Yellow Perch were exposed for $96 \mathrm{~h}$ or $10 \mathrm{~d}$ to $\mathrm{AgNP}$ and a significant increase in $m t$ mRNA levels of 2- to 3-fold was observed in the exposed fish relative to control fish (Martin et al. 2017a). Maes et al. (2013) analyzed metallothionein transcriptional levels in European eels (Anguilla anguilla) from several polluted sites and observed that $m t$ expression was reduced in fish with low energy reserves and reduced body condition. Therefore, the expression of metallothionein in Yellow Perch from the AgNP lake may have been modulated as a result of diminished energy levels in fish stressed by exposure to AgNP. At the level of individual fish, we observed suppressed prey consumption and reduced total metabolism in Yellow Perch exposed to AgNP, and a reduction in size-at-age in older fish. We also observed reduced size-at-age in 2016 in Yellow Perch from the reference lake, which may indicate a regional effect on growth in Yellow Perch in that year. However, our data indicate that the reduced size-at-age observed in 2014 and 2015 in Yellow Perch in the AgNP lake is more likely due to exposure to AgNP or its transformation products. We speculate that the cellularlevel effects of AgNP exposure that indicate stress in Yellow Perch were linked mechanistically to the reduced consumption of prey and reduced total metabolism of Yellow Perch from the AgNP lake. The energy demands of combating oxidative stress could have altered total metabolism, causing lethargy in Yellow Perch and reducing their ability to capture prey, ultimately reflected in reduced size-at-age. Consistent with these findings, exposure to AgNP was observed by Murray et al. (2017a) to induce higher cortisol levels in rainbow trout (Oncorhynchus mykiss). In this lab study with rainbow trout and in a subsequent study by the same authors, both growth and metabolic rates all tended to be lower with increasing concentrations of AgNP, although though non-significantly after 28 days of AgNP exposure (Murray et al. 2017a,b). Interestingly, the body condition of Yellow Perch was relatively stable in Yellow Perch from the AgNP lake whereas body condition was variable in Yellow Perch from the reference lake; that is, high in 2012 and consistently lower during 2014-2016. Body condition often scales positively with food availability (Rennie and Verdon 2008; Rennie et al. 2019). Thus, stable body condition may be an indicator of relatively stable per capita food availability in the AgNP lake, further indicating that the reductions in food 
consumption and metabolic costs in Yellow Perch after AgNP additions were likely not a result of reduced food availability.

At the population level, the density of Yellow Perch exposed to AgNP declined by nearly half during the experiment, while no such declines were observed in the Yellow Perch population in the reference lake. This reduction in population size may also explain the stable body condition observed in Yellow Perch that were exposed

502 to AgNP, as intraspecific competition for food would be reduced in conditions where there is a smaller population

503 size. The reduction in both population densities and consumption rates combined to yield estimates of gross consumption that were reduced by approximately $50 \%$ for Yellow Perch exposed to AgNP, for a reduction of

505 invertebrate biomass consumed of approximately $600 \mathrm{~kg} / \mathrm{ha}$ on an annual basis. Conversely, gross consumption rates

506 for Yellow Perch from the reference lake were relatively stable. Further, Yellow Perch exposed to AgNP fed

507 overwhelmingly on zooplankton and benthos, switching from zooplanktivory to benthivory when they reached sizes

508 of 75-100 mm (Hayhurst 2018), corresponding to the transition between age 2 and age 3 fish (Figure 4A).

509 Interestingly, most of the gross prey consumption in 2016 for Yellow Perch exposed to AgNP was determined by

510 younger (i.e., age 1 and 2) Yellow Perch that feed on zooplankton, as gross consumption by older age classes that

511 feed on zoobenthos declined precipitously. Without additional information on either resource partitioning (e.g., in

512 studies using stable isotopes) or production rates of either zooplankton or zoobenthos, it is unclear whether the

513 decline in the gross consumption of larger fish is driven by a lack of benthic food resources (i.e., indirect effect)

514 caused by exposure of benthos to AgNPs settling into sediments, or direct effects of AgNP in exposed fish.

515 However, the observed increased consumption by young Yellow Perch provides some evidence of post-addition 516 recovery for small fish that are planktivorous.

The biological responses observed in Yellow Perch in the present study are consistent with other examples

518 of biological effects described in the literature for fish exposed to nanoparticles. In studies with a range of fish

519 species exposed to AgNP, oxidative stress has been observed at cellular and molecular levels (Valerio-Carlson et al.

520 2008; Griffit et al. 2012; Pham et al. 2012; McShan et al. 2014; Bacchetta et al. 2017; Garcia et al. 2017; Martin et

521 al. 2017a). Rainbow trout exposed to low (0.3-50 $\mu \mathrm{g} / \mathrm{L})$ levels of AgNP for 28 days showed a significant stress

522 response via increased blood cortisol (Murray et al. 2017a) and these changes in cortisol levels may have been

523 associated with oxidative stress. While no previous studies have documented the effects of AgNP exposure on fish

524 bioenergetics, Beyers et al. (1999) observed reduced prey consumption and total metabolism in fish following 
exposure to other classes of contaminants. In laboratory studies with fish exposed to AgNP over relatively short periods of time, reduced metabolic performance was observed (Bilberg et al. 2010; Murray et al. 2017b), although the levels of exposure that elicited metabolic responses in these studies were too high to be considered environmentally relevant. However, chronic exposures to lower levels of AgNP, such as those that occurred in the AgNP lake may produce similar metabolic effects. For instance, Leadley et al. (2015) detailed how exposures to a range of contaminants (i.e., metals, pesticides, persistent organic pollutants, etc.) directly decrease the metabolic rates of fishes, either from a stressor response in energy allocation or a toxic interaction between the contaminant and the biochemical pathway regulating fish metabolism.

The sum of evidence from the present study indicates that there are linkages between responses observed across several levels of biological organization in Yellow Perch during the period of AgNP exposure and these responses are largely direct, as opposed to indirect effects on prey species. We speculate that negative impacts due to oxidative stress led to reduced prey consumption, metabolism, and growth among individual Yellow Perch, and that this ultimately led to reduced Yellow Perch densities and gross prey consumption rates. However, it cannot be entirely discounted that indirect effects related to prey availability could cause similar responses. While other studies have demonstrated that the simplified prey communities that occur in metal-contaminated lakes contributed to stunted growth in Yellow Perch populations due to energetic bottlenecks (Sherwood et al. 2000, 2002), these energetic bottlenecks are normally associated with increased metabolic costs (Sherwood et al. 2000), which is contrary to the decreased rates we observed here. Interestingly, metabolic patterns observed across all years in the reference lake are entirely consistent with expectations of changes in metabolic costs when switching from invertebrate to fish prey (Sherwood et al. 2002).

Based on the biological responses observed in Yellow Perch at multiple levels of biological organization in a whole-lake ecosystem, we make the case that exposure to AgNP and transformation products at low $\mu \mathrm{g} / \mathrm{L}$ concentrations was detrimental to the overall health of these fish. Our previous studies showed that AgNP and transformation products were distributed throughout the AgNP lake during the addition phase. Concentrations of Ag were in the low $\mu \mathrm{g} / \mathrm{L}$ range, with $11.5 \mu \mathrm{g} / \mathrm{L}$ detected as the highest concentration estimated from passive samplers (Martin et al. 2018) and $17.4 \mu \mathrm{g} / \mathrm{L}$ as the highest concentration measured directly in water samples (Conine et al. 2017). In contrast, very low concentrations of dissolved silver were detected in the water column during the addition phase (Conine et al. 2017; Martin et al. 2018). Analysis of water samples collected from the AgNP lake using single 
particle ICP-MS instrumentation showed that $\mathrm{Ag}$ in the nanoparticle size range (i.e., 14-72 nm) was present in the water column during AgNP additions at concentrations of approximately 1-5 $\times 10^{10}$ particles per litre (Martin et al. 2018). The concentrations of Ag during AgNP additions were about an order of magnitude higher than the Canadian water quality guideline for the protection of aquatic life ( $\mathrm{Ag}=0.25 \mu \mathrm{g} / \mathrm{L} ; \mathrm{CCME}, 2015)$. More work is needed to determine whether this guideline is protective for aquatic life exposed over the long-term to AgNP and its transformation products.

\section{REFERENCES}

Asharani PV, Lian WY, Gong Z, Valiyaveettil S (2008) Toxicity of silver nanoparticles in zebrafish models. Nanotech 19:1-8

Bacchetta C, Ale A, Simoniello MF, Gervasio S, Davico C, Rossi AS, Desimone MF, Poletta G, López G, Monserrat JM, Casenave J (2017) Genotoxicity and oxidative stress in fish after short-term exposure to silver nanoparticles. Ecol Indicat 76:230-239

Beyers DW, Rice JA, Clements WH, Henry CJ (1999) Estimating physiological cost of chemical exposure: integrating energetics and stress to quantify toxic effects in fish. Can J Fish Aquat Sci 56:814-822

Bilberg K, Malte H, Wang T, Baatrup E (2010) Silver nanoparticles and silver nitrate cause respiratory stress in Eurasian Yellow Perch (Perca fluviatilis). Aquat Toxicol 96:159-165

Bustin SA, Benes VB, Garson JA, Hellemans J, Huggett J, Kubista M, Mueller R, Nola T, Pfaffl MW, Shipley GL, Vandesompele J, Wittwer CT (2009) The MIQE guidelines: Minimum information for the publication of quantitative real-time PCR experiments. Clin Chem 55: 611-622

Buzea C, Pacheco I, Robbie K (2007) Nanomaterials and nanoparticles: Sources and toxicity. Biointerphases 2:MR17-MR71

CCME (2015) Canadian water quality guidelines for the protection of aquatic life: Silver. In: Canadian environmental quality guidelines, Canadian Council of Ministers of the Environment, Winnipeg, MB, Canada, $16 \mathrm{p}$

Cappello T, Brandão F, Guilherme S, Santos MA, Maisano M, Mauceri A, Canário J, Pacheco M, Pereira P (2016) Insights into the mechanisms underlying mercury-induced oxidative stress in gills of wild fish (Liza aurata) combining ${ }^{1} \mathrm{H}$ NMR metabolomics and conventional biochemical assays Sci Total Environ 548-549:13-24 
Carlson C, Schrand AM, Braydich-Stolle LK, Hess KL, Jones RL, Schlager JJ, Hussain SM (2008) Unique cellular interaction of silver nanoparticles: Size-dependent generation of reactive oxygen species. $J$ Phys Chem B 112:13608-13619

Chae YJ, Pham CH, Lee J, Bae E, Yi J, Gu MB (2009) Evaluation of the toxic impact of silver nanoparticles on Japanese medaka (Oryzias latipes). Aquat Toxicol 94:320-327

Colman BP, Espinasse B, Richardson CJ, Matson CW, Lowry GV, Hunt DE, Wiesner MR, Bernhardt ES (2014) Emerging contaminant or an old toxin in disguise? Silver nanoparticle impacts on ecosystems. Environ Sci Technol 48:5229-5236

Conine AL, Rearick DC, Paterson MJ, Xenopoulos MA, Frost PC (2018) Addition of silver nanoparticles has no long-term effects on natural phytoplankton community dynamics in a boreal lake. Limnol Oceanog Lett 3(4):311-319

Cummins KW, Wuycheck JC (1971) Caloric equivalents for investigations in ecological energetics. International Association of Theoretical and Applied Limnology 18. E. Schweizerbart, Stuttgart, Germany

Eckmann R (2004) Overwinter changes in mass and lipid content of Perca fluviatilis and Gymnocephalus cernuus. J Fish Biol 65:1498-1511

Farmen E, Mikkelsen HN, Evensen O, Einset J, Heier LS, Rosseland BO, Salbu B, Tollefsen KE, Oughton DH (2012) Acute and sub-lethal effects in juvenile Atlantic salmon exposed to low $\mu \mathrm{g} / \mathrm{L}$ concentrations of $\mathrm{Ag}$ nanoparticles. Aquat Toxicol 108:78-84

Ferriss BE, Essington TE (2014) Can fish consumption rate estimates be improved by linking bioenergetics and mercury mass balance models? Application to tunas. Ecol Model 272:232-241

Fox J, Weisberg S (2011) An R Companion to Applied Regression, $2^{\text {nd }}$ edn. Sage

Garner KL, Suh S, Lenihan HS, Keller AA (2015) Species sensitivity distributions for engineered nanoparticles. Environ Sci Technol 49:5753-5759

Gottschalk F, Sonderer T, Scholz RW, Nowack B (2010) Possibilities and limitations of modeling environmental exposure to engineered nanomaterials by probabilistic material flow analysis. Environ Toxicol Chem 29:1036-1048

Gottschalk F, Sun T, Nowack R (2013) Environmental concentrations of engineered nanomaterials: Review of modeling and analytical studies. Environ Pollut 181:287-300 
608

609

610

611

612

613

614

615

616

617

618

619

620

621

622

623

624

625

626

627

628

629

630

631

632

633

634

635

Hanson PC, Johnson TB, Schindler DE, Kitchell JF (1997) Fish Bioenergetics 3.0. University of Wisconsin, Sea Grant Institute, Technical Report WISCU-T-97-001, Madison, WI, USA

Hayes JD, McLellan LI (1999) Glutathione and glutathione-dependent enzymes represent a co-ordinately regulated defence against oxidative stress. Free Radical Res 31:273-300

Hayhurst LD (2018) Bioenergetic evaluation of a whole-lake nanosilver addition on Yellow Perch (Perca flavescens). Dissertation, Lakehead University

Isermann DA, Knight CT (2005) A computer program for age-length keys incorporating age assignment to individual fish. NA J Fish Manag 25:1153-1160

Kennedy AJ, Hull MS, Bednar AJ, Goss JD, Gunter JC, Bouldin JL, Vikesland PJ, Steevens JA (2010) Fractionating nanosilver: Importance for determining toxicity to aquatic test organisms. Environ Sci Technol 44:95719577

Kimura DA (1977) Statistical assessment of the age-length key. J Fish Res Board Can 34:317-324

Kitchell JF, Stewart DJ, Weininger D (1977) Applications of a bioenergetics model to yellow Yellow Perch (Perca flavescens) and walleye (Stizostedion vitreum vitreum). J Fish Res Board Can 34:1922-1935

Laban G, Nies LF, Turco RF, Bickham JW, Sepúlveda MS (2010) The effects of silver nanoparticles on fathead minnow (Pimephales promelas) embryos. Ecotoxicology 19:185-95

Leadley TA, McLeod AM, Johnson TB, Heath D, Drouillard KG (2015) Uncovering adaptive versus acclimatized alterations in standard metabolic rate in brown bullhead (Ameiurus nebulosus). Can J Fish Aquat Sci 73:973-981

Maillard J-Y, Hartemann P (2013) Silver as an antimicrobial: facts and gaps in knowledge. Crit Rev Microbiol 39(4):373-383

Martin JD, Colson T-L, Langlois VS, Metcalfe CD (2017a) Biomarkers of exposure to nanosilver and silver accumulation in yellow Yellow Perch (Perca flavescens). Environ Toxicol Chem 36:1211-1220

Martin JD, Telgmann L, Metcalfe CD (2017b) A method for preparing silver nanoparticle suspensions in bulk for ecotoxicity testing and ecological risk assessment. Bull Environ Contam Toxicol 98:589-594

Martin JD, Frost PC, Hintelmann H, Newman K, Paterson MJ, Hayhurst L, Rennie MD, Xenopoulos MA, Yargeau V, Metcalfe CD (2018) Accumulation of silver in Yellow Perch (Perca flavescens) and Northern Pike (Esox lucius) from a lake dosed with nanosilver. Environ Sci Technol 52:11114-11122 
Massarsky A, Trudeau VL, Moon TW (2014) Predicting the environmental impact of nanosilver. Environ Toxicol Pharmacol 38:861-873

Maes GE, Raeymaekers, JAM, Hellemans B, Geeraerts C, Parmentier K, De Temmerman L, Volckaert FAM, Belpairte C (2013) Gene transcription reflects poor health status of resident European eel chronically exposed to environmental pollutants. Aquat Toxicol 126:242-255.

McShan D, Ray PC, Yu H (2014) Molecular toxicity mechanisms of nanosilver. J Food Drug Anal 22:116-127.

Morgan TP, Grosell M, Playle RC, Wood CM (2004) The time course of silver accumulation in rainbow trout during static exposure to silver nitrate: Physiological regulation or an artifact of the exposure conditions? Aquat Toxicol 66:55-72

Murray L, Rennie MD, Enders E, Pleskach K, Martin J (2017a) Effect of nanosilver on cortisol release and morphometrics in rainbow trout (Oncorhynchus mykiss). Environ Toxicol Chem 36(6):1606-1613

Murray L, Rennie MD, Svendsen JC, Enders EC (2017b) Effect of nanosilver on metabolism in rainbow trout (Oncorhynchus mykiss): An investigation using different respirometric approaches. Environ Toxicol Chem $36: 2722-2729$

Notter DA, Mitrano DM, Nowack B (2014) Are nanosized or dissolved metals more toxic in the environment? A meta-analysis. Environ Toxicol Chem 33:2733-2739

Nowack, B, Ranville J, Diamond S, Gallego-Urrea J, Metcalfe C, Rose J, Horne A, Koelmans AA, Klaine SJ (2012) Potential scenarios for nanomaterial release and subsequent alteration in the environment. Environ Toxicol Chem 31:50-59

Ogle DH (2016) A computer program for age-length keys incorporating age assignment to individual fish. NA J Fish Manag 25:1153-1160

Ogorek J, Dewild J (2010) Analysis of methylmercury in biological samples by cold vapor atomic fluorescence detection with the Brooks-Rand "MERX" automated methylmercury analytical system. Brooks-Rand 13p

Ontario Benthos Biomonitoring Network: Protocol Manual (2007) Jones C, Somers KM, Craig B, Reynoldson TB (eds) Ontario Ministry of the Environment and Climate Change. Accessed https://desc.ca/sites/default/files/OBBN2007finalapril18c.pdf

Pazzia I, Trudel M, Ridgway M, Rasmussen JB (2002) Influence of food web structure on the growth and bioenergetics of lake trout (Salvelinus namaycush). Can J Fish Aquat Sci 59:1593-1605 
664

665

666

667

668

669

670

671

672

673

674

675

676

677

678

679

680

681

682

683

684

685

686

687

688

689

690

691

Pena EA, Slate EH (2006) Global validation of linear model assumptions. J Amer Stat Assoc 101: $341-354$

Pham CH, Yi J, Gu MB (2012) Biomarker gene response in male medaka (Oryzias latipes) chronically exposed to silver nanoparticle. Ecotoxicol Environ Safe 78:239-245

Pierron F, Bourret V, St-Cyr J, Campbell PGC, Bernatchez L, Couture P (2009) Transcriptional responses to environmental metal exposure in wild yellow Yellow Perch (Perca flavescens) collected in lakes with differing environmental metal concentrations (Cd, Cu, Ni). Ecotoxicol 18:620-631

Pulit-Prociak J, Stokłosa K, Banach M (2014) Nanosilver products and toxicity. Environ Chem Lett 13:59-68

Quinn GP, Keough MJ (2002) Experimental Design and Data Analysis for Biologists. Cambridge University Press, New York

R Core Team (2014) R: A language and environment for statistical computing. R Foundation for Statistical Computing, Vienna, Austria. Accessed http://R-project.org

Rand PS, Stewart DJ (1998) Prey fish exploitation, salmonine production, and pelagic food web efficiency in Lake Ontario. Can J Fish Aquat Sci 55:318-327

Rearick DC, Telgmann L, Hintelmann H, Frost PC, Xenopoulos MA (2018) Spatial and temporal trends in the fate of silver nanoparticles in a whole-lake addition study. PlosONE 13(8):e0201412

Reidy B, Haase A, Luch A, Dawson KA, Lynch I (2013) Mechanisms of silver nanoparticle release, transformation and toxicity: A critical review of current knowledge and recommendations for future studies and applications. Materials 6:2295-2350

Rennie MD, Johnson TB, Sprules WG (2012) Energy acquisition and allocation patterns of lake whitefish (Coregonus clupeaformis) are modified when dreissenids are present. Can J Fish Aquat Sci 69:41-59

Rennie MD, Purchase CF, Shuter BJ, Collins NC, Abrams PA, Morgan GE (2010) Prey life-history and bioenergetics response across a predation gradient. J Fish Biol 77:1230-1251

Rennie MD, Venturelli PA (2015) The ecology of lifetime growth in percid fishes. In: Kestemont P, Dabrowski K, Summerfelt RC (eds) Biology and Culture of Percid Fishes: Principles and Practices. Springer, Netherlands, pp 499-536

Schindler DE, Eby LA (1997) Stoichiometry of fishes and their prey: implications from nutrient recycling. Ecology $78: 1816-1831$

Schnabel ZE (1938) The estimation of the total fish population of a lake. Am Math Month 45:348-352 
Sherwood GD, Kovecses J, Hontela A, Rasmussen JB (2002) Simplified food webs lead to energetic bottlenecks in polluted lakes. Can J Fish Aquat Sci 59:1-5

Sherwood GD, Rasmussen JB, Rowan DJ, Brodeur J, Hontela A (2000) Bioenergetic costs of heavy metal exposure in yellow Yellow Perch (Perca flavescens): in situ estimates with a radiotracer (Cs-137) technique. Can J Fish Aquat Sci 57(2):441-450

Smokorowski KE, Randall RG (2017) Cautions on using the Before-After-Control-Impact design in environmental effects monitoring programs. FACETS 2:212-232

Sun TY, Gottschalk F, Hungerbühler K, Nowack B (2014) Comprehensive probabilistic modelling of environmental emissions of engineered nanomaterials. Environ Poll 185:69-76

Trudel M, Rasmussen J (2001) Predicting mercury concentration in fish using mass balance models. Ecol Applic 11(2):517-529

Trudel M, Tremblay A, Schetagne R, Rasmussen JB (2000) Estimating food consumption rates of fish using a mercury mass balance method. Can J Fish Aquat Sci 57:414-428

Trudel M, Tremblay A, Schetagne R, Rasmussen JB (2001) Why are dwarf fish so small? An energetic analysis of polymorphism in lake whitefish (Coregonus clupeaformis). Can J Fish Aquat Sci 58:394-405

US Environmental Protection Agency (1998) Method 7473 (SW-846): Mercury in Solids and Solutions by Thermal Decomposition, Amalgamation, and Atomic Absorption Spectrophotometry. Revision 0. United States Environmental Protection Agency, Washington, D.C., USA

US Environmental Protection Agency (2001) Method 1630: Methyl mercury in water by distillation, aqueous ethylation, purge and trap, and CVAFS. EPA 821-R-01-020. United States Environmental Protection Agency, Washington, D.C., USA

Valerio-Garcia RC, Carbajal-Hernandez AL, Martinez-Ruiz EB, Jarquin-Diaz VH, Haro-Perez C, MartinezJeronimo F (2017) Exposure to silver nanoparticles produces oxidative stress and affects macromolecular and metabolic biomarkers in the godeid fish Chapalychthys pardalis. Sci Total Environ 583:308-318

Völker C, Oetken M, Oehlmann J (2013) The biological effects and possible modes of action of nanosilver Rev Environ Contam Toxicol 233:81-106

Wang Z, Chen J, Li X, Shao J, Peijenburg WJGM (2012) Aquatic toxicity of nanosilver colloids to different trophic organisms: contributions of particles and free silver ion. Environ Toxicol Chem 31(10):2408-2413 
Tables

721 Table 1 Summary data for Yellow Perch collected for biomarker analysis of liver tissues in the AgNP lake and

722 reference lakes 239, 240, and 383. Note that reference lake refers to Lake 239, unless otherwise specified.

\begin{tabular}{clcl}
\hline \multirow{2}{*}{ Phase } & Lake & Sacrificed Perch & Biomarkers Measured \\
& & $(\#)$ & \\
\hline \multirow{2}{*}{ Pre-addition } & AgNP lake & 72 & Glutathione and TBARS \\
& Reference lake & 36 & Expression of genes related to oxidative stress, \\
& Reference Lake 240 & 24 & heat shock proteins, and metallothionein \\
\hline \multirow{2}{*}{2013} & AgNP lake & 24 & \\
Pre-addition & Reference lake & 24 & Glutathione and TBARS \\
& & 24 & Expression of genes related to oxidative stress, \\
& AgNP lake & & heat shock proteins, and metallothionein \\
\hline \multirow{2}{*}{ 2014 } & Reference lake & 60 & Glutathione and TBARS \\
& & 60 & Expression of genes related to oxidative stress, \\
& AgNP lake & & heat shock proteins, and metallothionein \\
\hline Year 2 addition & Reference lake & 24 & Glutathione and TBARS \\
\hline
\end{tabular}


724 Table 2 Summary data for Yellow Perch collected in the summer (July and August) and fall (September and

725 October) for bioenergetics analysis (estimation of consumption and metabolic costs) in the AgNP lake and reference

726 lake.

\begin{tabular}{clcc}
\hline \multirow{2}{*}{ Phase } & \multirow{2}{*}{ Season } & \multicolumn{2}{c}{ Sacrificed Perch (\#) } \\
& & AgNP Lake & Reference Lake \\
\hline 2012 & SUMMER & 20 & 16 \\
Pre-addition & FALL & 29 & 26 \\
\hline 2014 & SUMMER & 21 & 27 \\
\cline { 2 - 4 } Year 1 addition & FALL & 24 & 23 \\
\hline 2015 & SUMMER & 26 & 22 \\
\cline { 2 - 4 } Year 2 addition & FALL & 22 & 29 \\
\hline 2016 & SUMMER & 24 & 21 \\
\cline { 2 - 4 } Post-addition & FALL & 21 & 20 \\
\hline
\end{tabular}

727 
A) $g p x$
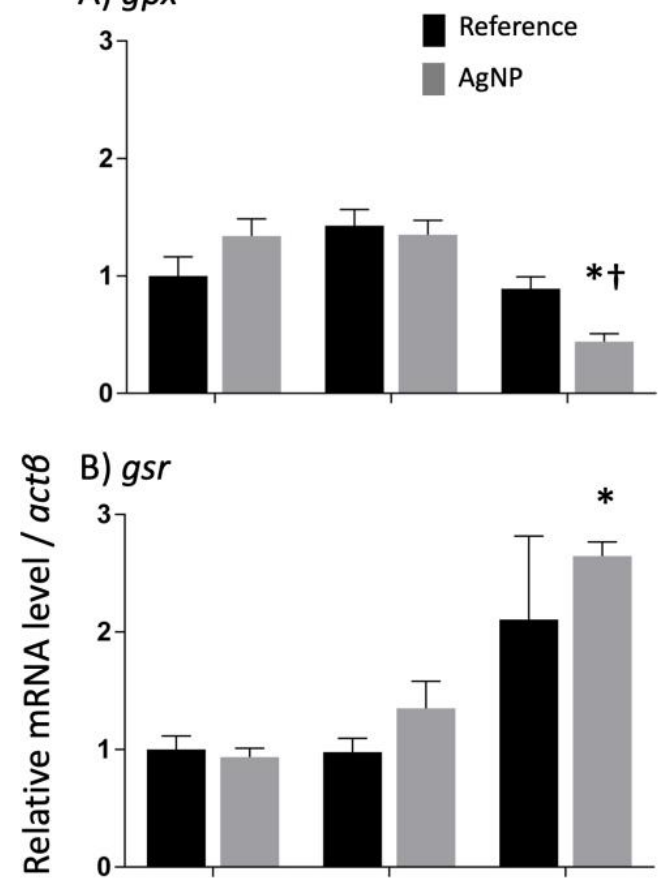

C) $m t$

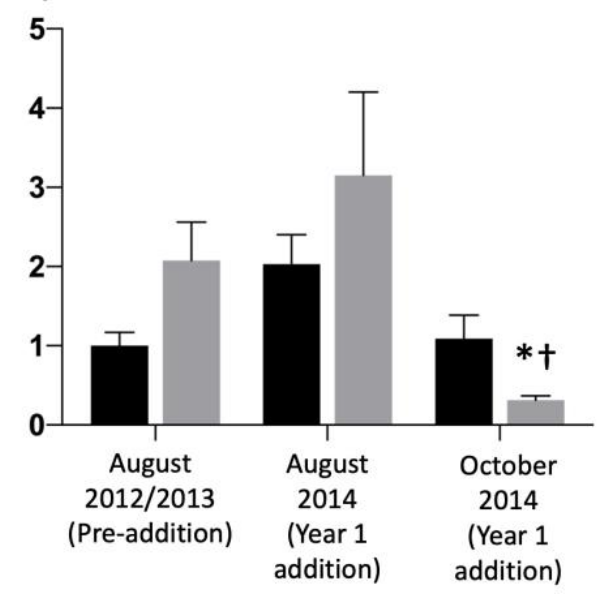

730 Figure 1 Mean \pm standard error of the relative expression of (A) glutathione peroxidase (gpx), (B) glutathione 731 reductase $(\mathrm{gsr})$, and $(\mathrm{C})$ metallothionein $(\mathrm{mt})$ genes in liver of Yellow Perch collected from the AgNP lake and

732 reference lakes over a pre-addition phase and in Year 1 of the AgNP addition phase of the study. Asterisk (*)

733 represents a significant difference in expression from pre-addition phase in the same lake, and dagger $(\dagger)$ represents

734 a significant difference in expression from the reference lake during the same collection phase. 

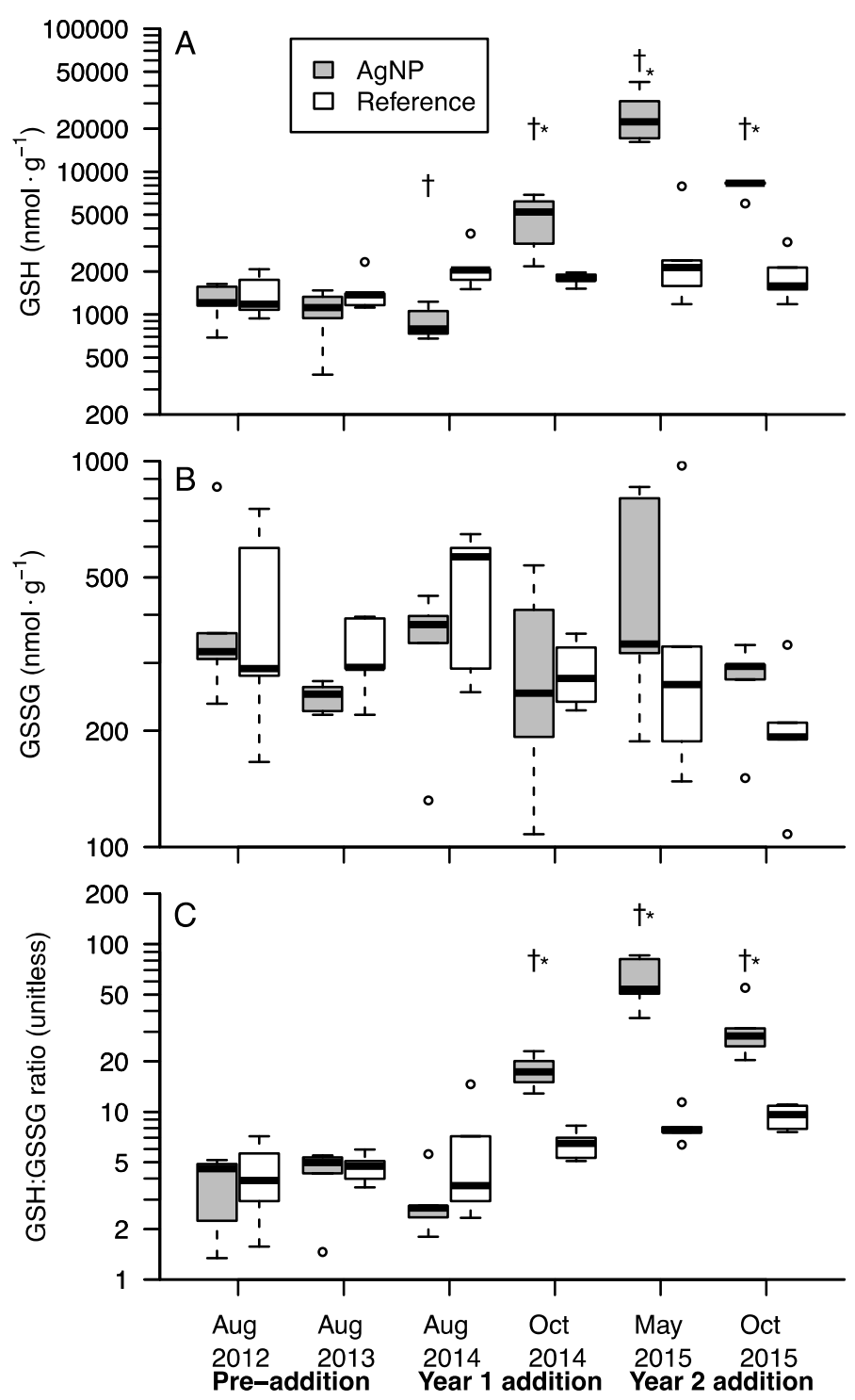

736 Figure 2 Mean, range, standard error of the concentrations (mmol per gram wet weight), and ratios of the forms of

737 glutathione in the livers of Yellow Perch collected from the AgNP lake and reference lakes over the pre-addition

738 phase and in Years 1 and 2 of the AgNP addition phases of the study. (A) reduced glutathione (GSH), (B) oxidized

739 glutathione (GSSG), and (C) ratio of reduced to oxidized glutathione. Asterisk $(*)$ represents a significant difference

740 in expression from pre-addition phase in the same lake and dagger $(\dagger)$ represents a significant difference in

741 expression from the reference lake during the same collection phase. Note log scale on y-axis. 


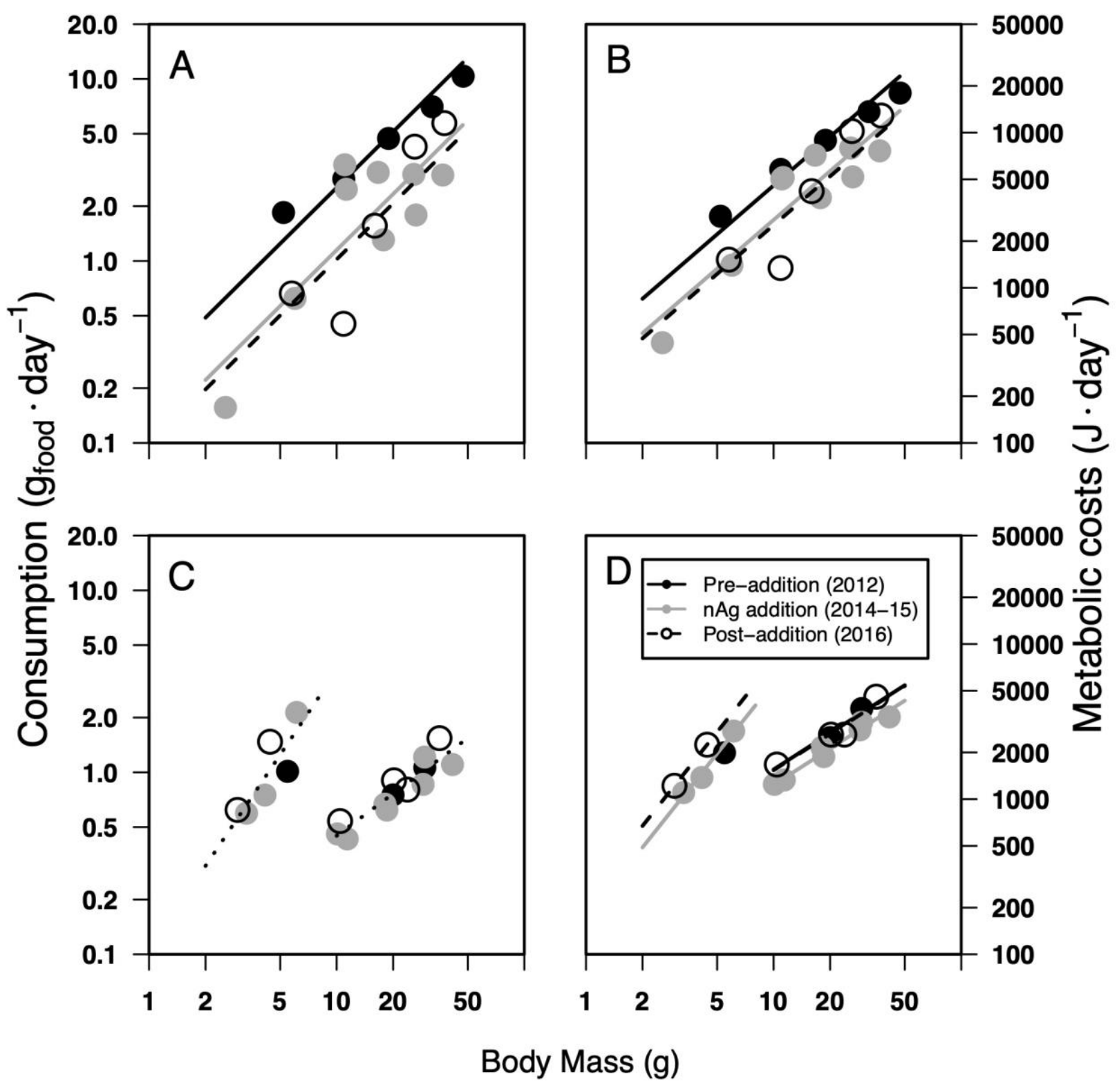

Figure 3 Bioenergetic estimates of Yellow Perch consumption (grams of food per day, A and C) and total

744 metabolism (Joules per day, B and D) in the AgNP lake (A and B) and the reference lake (C and D) across three

745 separate time periods. Time periods are pre-addition (2012, closed black symbols and solid lines), during AgNP

746 additions (2014-15, closed grey symbols and solid grey lines), and post-addition (2016, open symbols and dashed

747 lines). Consumption and respiration costs are represented by multiple lines in the reference lake (small fish are

748 zooplanktivorous, large fish are piscivorous), whereas bioenergetic estimates in the AgNP lake were more

749 continuous. Dotted line in (C) is a common slope among all time periods (no significant differences in consumption

750 among time periods in the reference lake). Note log scaling on both axes. 


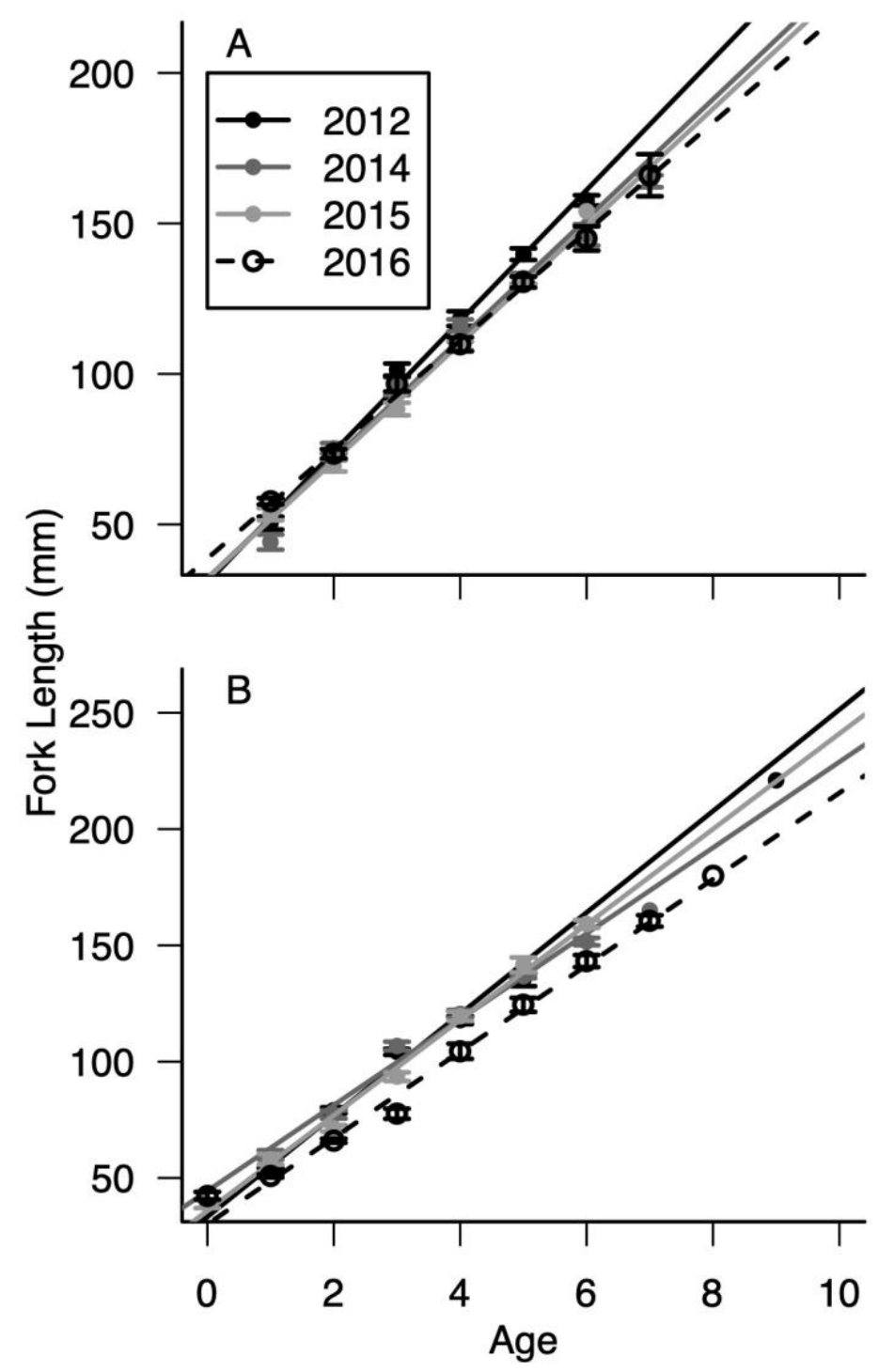

751

752 Figure 4 Comparisons of Yellow Perch fork length at age among years (2012 pre-addition, 2014-15 AgNP addition,

753 and 2016 post-addition) in the AgNP lake (A, top panel) and the reference lake (B, bottom panel). 

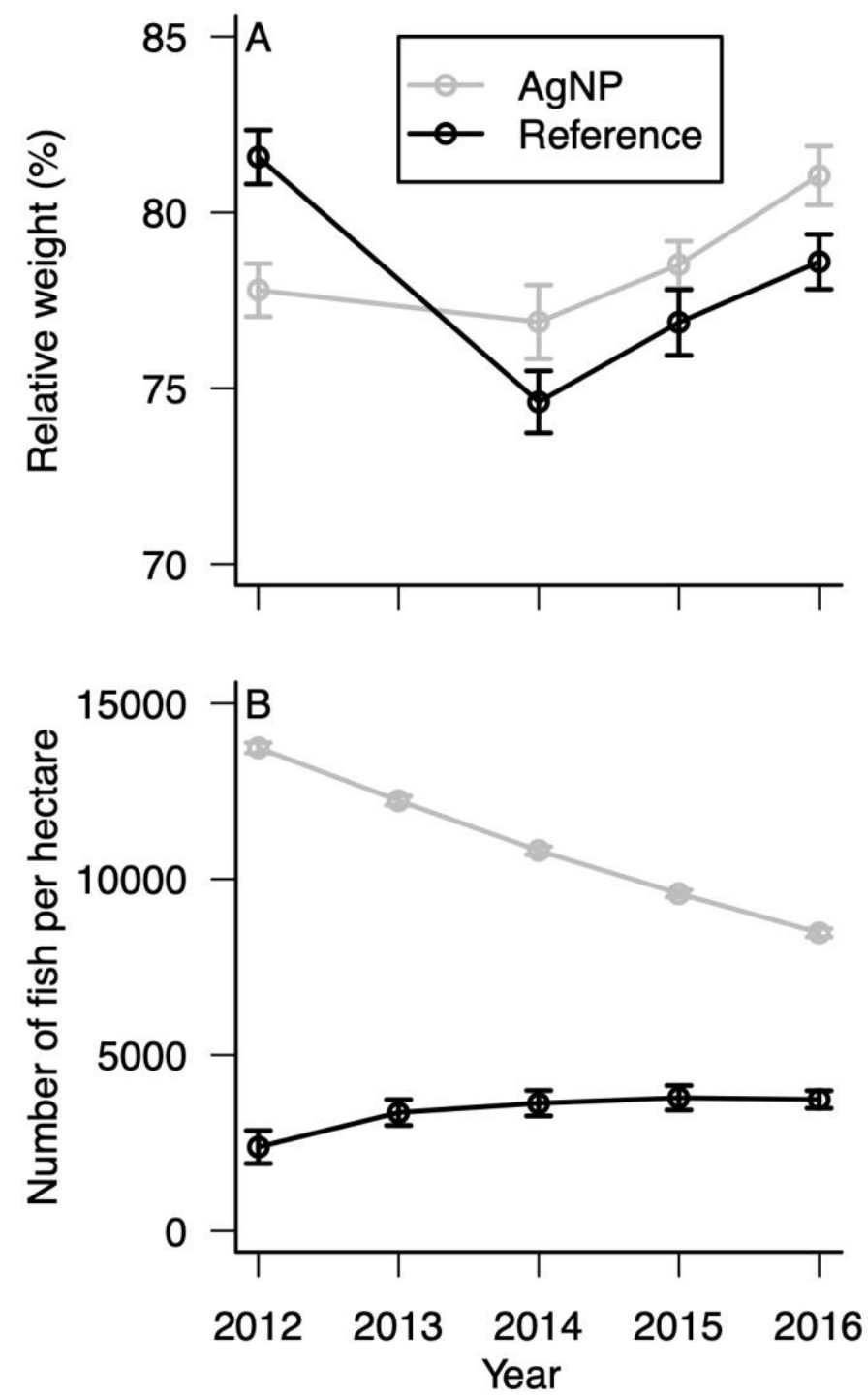

755 Figure 5 Changes in body condition and population density of Yellow Perch before, during, and after AgNP

756 additions. (A) Body condition (expressed as relative weight or percentage of standard weight for the species) of

757 Yellow Perch in a lake with AgNP added (grey) and an unmanipulated reference lake (black) before (2012), during

758 (2014-15), and after (2016) the period of AgNP additions. (B) Areal density (number per hectare) of Yellow Perch 759 in the AgNP lake and reference lake. 


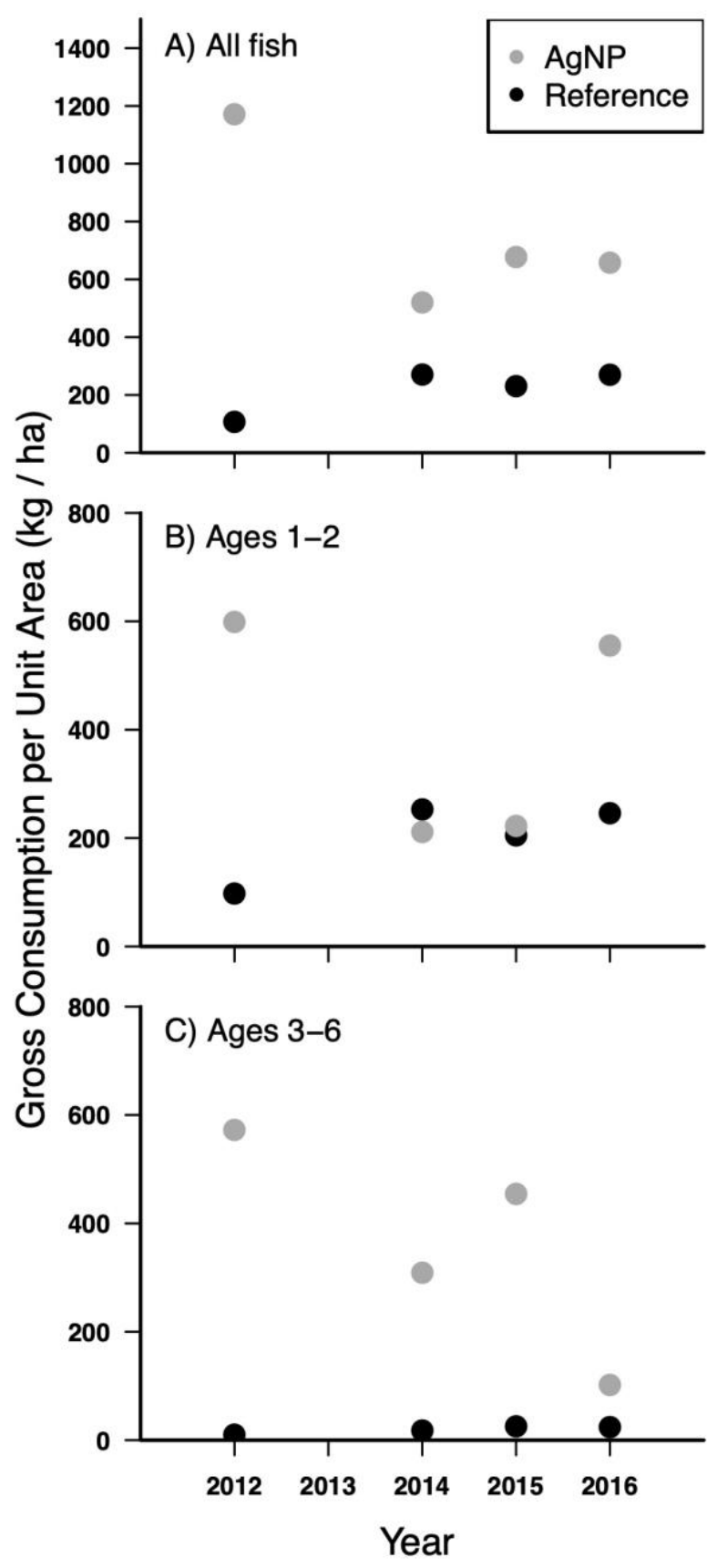

Figure 6 Gross consumption by Yellow Perch in the AgNP lake (grey symbols) and tbe reference lake (black

762 symbols). (A) All Yellow Perch combined, (B) Gross consumption by ages $1 \& 2$ Yellow Perch only, and (C) Gross

763 consumption by ages 3 to 6 Yellow Perch only. Sum of values in panels (B and C) are those shown in (A). 